\title{
Nothing to see here
}

\section{Based on one company's past poor publishing practices, a top-tier medical journal misguidedly stigmatizes any paper from industry.}

Th he Journal of the American Medical Association (JAMA) played a considerable part in manufacturing media outrage last month over an article 'revealing' Merck's use of ghostwriters and rubber stamp experts in the preparation of clinical research articles on Vioxx (rofecoxib). Although the JAMA article $(299,1800-1812,2008)$ revealed nothing new about the ghostwriting practice and so-called 'guest' authorship, the JAMA editors nevertheless felt moved to introduce a new, stricter set of policies on authorship and conflicts of interest.

The JAMA paper was based on thousands of internal memos that have come to light in the litigation surrounding Vioxx. With access to over 200,000 documents, four authors of the piece, all of whom were all involved as consultants or lawyers for the plaintiffs in the recent Vioxx litigation, had an insider view of the way Merck managed its relationships with potential academic authors on over 96 research and review articles connected with pivotal Vioxx trials.

The analysis in the JAMA paper is part fact and part inference. Some research articles on the Vioxx clinical trials were written by Merck insiders, who later appear as authors on the final published version, although seldom as first authors. The implication is that the first authors had little to do certainly with the writing, but possibly with the project itself. The JAMA paper also points out that some review articles touting Vioxx were written in toto by paid medical writers, something that was not apparent in the final published version, which often had a single academic author.

This is not exactly shocking. Pharmaceutical research is a team effort in which everyone in the team has different jobs. Some people do clinical research, others write papers. Not necessarily a big deal, or a big surprise. And certainly not unknown elsewhere in the pharma industry. Unsurprisingly, some of the authors on the papers have taken offense at the implication that they were not involved with the study.

A second problem is that JAMA apparently did not apprise Merck of what they were intending to publish, nor did it provide them with an opportunity to respond. That left the company with only the press to air their side of the story, certainly not any way to get to the bottom of the issue or promote a healthy exchange of views.

This is important because the whole analysis may not reflect current reality. Merck in 2008 is not publishing as it was over five years ago. The work on Vioxx predates the guidelines that Merck and other pharma companies now follow, such as those issued by the Council of Science Editors in 2003 (Curr. Med. Res. Opin. 19, 149-154). Indeed, no one at JAMA bothered to find out that Merck adopted as its policy for authorship the International Committee of Medical Journal Editors' guidelines (http://www.icmje.org/).

In an accompanying JAMA editorial (299, 1833-1835, 2008), the editors provide many sensible recommendations for cracking down on ghostwriting and guest authors. For example, they recommend ensuring that papers report the contributions of all authors to a piece of work and ensuring the disclosure of financial interests. The former are requested voluntarily as Nature and Nature research journal policy, whereas competing financial interest disclosures are a requirement of publication (http://www.nature.com/authors/editorial_policies/index.html).

But the JAMA editorial then goes too far, leaping on the findings to make recommendations that are unwarranted, not to say discriminatory, against the body corporate. In recommendation 4 , for example, the editors imply that any research associated with "industry" is potentially tainted. In essence, the editorial calls for journal editors to take into account all financial support and financial relationships when deciding whether to publish a manuscript at all.

One company's blurred practice does not make a whole industry culpable. The journal would be equally justified (that is, not justified at all) in calling for a ban on all papers from companies beginning with the letter ' $\mathrm{M}$ ', or all people from New Jersey, or all papers on Vioxx regardless of affiliation. Just because Merck has followed bad publishing practice for certain Vioxx papers, why should the rest of industry be penalized?

What the proposed restrictions highlight, in fact, is that a professional body like the American Medical Association feels incapable of conducting peer review of the content of its papers. That perhaps tells us as much about medical professionals and their associations as it tells us about the mechanics of pharmaceutical company research. Or it tells us that something is wrong with the 'scientific publishing' industry and its drivers. Surely, for both groups, the criteria for publishing ought to be the quality of the work, not how the work was supported or who wrote the paper

In recommendation 5, the JAMA editors call for sponsored research not to be solely in the hands of the sponsoring company. Rather, they propose that academic researchers who are not employed by the company should bear primary responsibility for collecting, analyzing and reporting data. So, who would these academics be, and what constitutes 'being in the employ'? How would this work for companies that don't partner with academics? Would accepting research support disqualify academics? Would receiving honoraria disqualify them?

Ghostwriting and guest authorship run contrary to the Corinthian spirit of scientific publishing. Although that spirit may have disappeared since the days when science was the exclusive province of the enthusiastic and moneyed amateur, companies that use ghostwriters and rubberstamp experts as authors of their papers reinforce the impression that industry's only interest in publishing is to dress up marketing as science. But the editors of JAMA and other journals would do well to focus on content, not process. JAMA's attack casts a cloud over the entire industry. Stigmatizing any paper that comes from the private sector on the basis of an analysis of one company's poor publishing practices over five years ago is not only unjustified, it is discrimination pure and simple. 